International Journal of Stem Cell Research and Transplantation (IJST)

ISSN: 2328-3548

\title{
Isolation Stem Cells From Human Dental Pulps And Differentiation Them To Adiposite And Osteoblast
}

Jabari $\mathrm{F}^{1^{*}}$, Mohammadnejad J2 Yavari $\mathrm{K}^{3}$

Research Article

${ }^{1 *}$ Faculty of New Sciences and Technologies, University of Tehran, Tehran, Iran.

${ }^{2}$ Professor assistance, Department of Life Science Engineering, Faculty of New Sciences and Technologies,

University of Tehran, Tehran, Iran

Professor assistance, Biotechnology lab, Nuclear Science and Technology Research institute, (NSTRI), atomic

nuclear energy organization, Tehran, Iran.

\section{Abstract}

Objective: in this study we tried to isolated stem cells from human primary dental pulp. These cells are capable of differentiating into a variety of cell types including neural cells, adipocytes, and odontoblasts, osteoblast

Background \& Aim: Among different source for stem cells, less attention has been paid to the human dental pulp. Human dental pulps are the best and new source for stem cells, and have potential to different to all kinds of cells. So the aim of this study was to evaluate the pulp ability for produce stem cells.

Materials and Methods: Normal exfoliated human deciduous incisors collected from6- to 12-years-old children. The pulp was separated from the crown and digested with trypsin stem cells cultured in DMEM(Dulbecco's Modified Eagle's Medium), supplemented with $20 \%$ fetal bovine serum in a $37^{\circ} \mathrm{C}$ incubator with $5 \% \mathrm{co}_{2}$. The cells were differentiated into the osteoblastic and adipocytic lineages in different subcultures

Results: Stem cells are able to growth and proliferate unlimitedly and differentiate to all kinds of the cells in human body. Their life time is very long and they remain their potential for long periods of time. For this reasons today many physicians and researchers consider them as a therapeutic agent to cure diseases. One of the most important advantaged of dental pulp stem cells, is that isolated from primary dental, that are thrown away usually. Various scaffolds have been used to cell culture. Stem cells were observed to grow in colony forming units, mainly composed of a fibroblast-like cell population.

Conclusion: This study show that pulp contains cells with high proliferation capacity. The cells can be used for clinical application. Cells can be considered as an easy accessible source of mesenchymal stem cells for stem cell research and tissue engineering.

Key Words: Dental Pulp Stem Cell; Supernumerary Tooth; Differentiation; Adiposite; Osteoblast.

\section{*Corresponding Author:}

Farzaneh Jabari,

Faculty of New Sciences and Technologies, University of Tehran,

Tehran, Iran.

E-mail: jabarifarzane@yahoo.com

Received: October 10, 2013

Accepted: October 28, 2013

Published: October 31, 2013

Citation: Jabari F, Mohammadnejad J, Yavari K. (2013). Isolation Stem Cells from Human Dental Pulps and Differentiation Them to Adiposite and Osteoblast, Int J Stem Cell Res Transplant, 01(06), 32-36. doi: http://dx.doi.org/10.19070/2328-3548-130006

Copyright: Jabari $\mathbf{F}^{\circ}$ 2013. This is an open-access article distributed under the terms of the Creative Commons Attribution License, which permits unrestricted use, distribution and reproduction in any medium, provided the original author and source are credited.

\section{Introduction}

here are several differences between primary teeth and permanent teeth in terms of their evolution process, tissue architecture and their function. Stem Cells from Human Exfoliated Deciduous Teeth (SHED) have greater proliferative power in comparison to dental pulp stem cell (DPSC). Besides, these primary teeth are much smaller in size and much brighter than permanent ones. they have short Bulbaceous crown, tight Cervical canal, small rodent, narrow root, thin dentin and enamel thickness; with much wider teeth marrow which make them superior to permanent teeth. it has been shown that primary dental pulp contain stem cells which can be used as cell resource for therapeutic applications like umbilical cord stem cells. To engineer tissues in vitro, the first step is to isolate cells with the right phenotype and propagate them in suitable culturing environments. Normally, dental pulp stem cells are grown on a two-dimensional surface before being transferred to a three-dimensional scaffold construct. There was no report to our knowledge about the derivation of DPSCs from the other tooth types. The incidence of supernumerary teeth varies depending on the literature source. Here, we presented our recent success in the isolation and characterization of DPSCs from the pulp tissue of a supernumerary tooth.

\section{Materials and Methods}

Primary teeth falling and their replacement with permanent ones, is physiologically an active process which involves the genesis of permanent teeth and the absorption of primary teeth roots si- 
multaneously. it has been shown that primary dental pulp contain stem cells which can be used as cell resource for therapeutic applications like umbilical cord stem cells. Healthy dental were collected from 8-12 children from dental clinics. Tooth surfaces were cleaned and cut around the cementum-enamel junction by using sterilized dental fissure burs to reveal the pulp chamber. The isolation process would take place in 2 different methods: The enzymatic digestion method: in this method the tissue sample is placed in $3 \mathrm{mg} / \mathrm{ml}$ type I collagenase plus $4 \mathrm{mg} / \mathrm{ml}$ dyspase, For" 30-60 "minutes at $37^{\circ} \mathrm{C}$ after cutting into small slices. The resulting cell suspension is then passed through a 0.2 micrometer filter and cultured with 20\% Fetal Bovine Serum (FBS) supplemented with $100 \mu \mathrm{mol}$ of ascorbic acid 2-phosphate and $100 \mathrm{unit} / \mathrm{ml}$ penicillin in a $\mathrm{CO}_{2}$ cell culture incubator. These cells are called human dental pulp cells/digestion (HDPC-d). The second method is a subsidiary one in which the cells are cultured in 6-well plates with DMEM(Dulbecco's Modified Eagle's Medium) culture medium supplemented with all above mentioned supplements. After reaching a suitable confluency, they are transferred to a culture flask and grown continuously there; now they are called human dental pulp cells/outgrown (HDPC-O). Both can be cryopreserved in liquid nitrogen. Cells in both groups are then investigated, using Broumodoxy yuridin. cells are randomly countered under light microscopy after fixation and dying processes. HDPC-d have greater proliferative rate in comparison to the second group.

\section{Differentiation}

After a bout 2 months of isolation, cells colonies in the flask were easily visible. For confirm that the cells are stem cells, we differentiated cells to adiposite and osteoblast .stem cells were in 6 walls plate with DMEM (Dulbecco's Modified Eagle's Medium), then osteogenic and adipogenic medium added. Plate put in incubator for 21 day, the culture medium exchanged in this period after 21 day we use oil red and alizarin red for staining.

\section{Results}

The stem cells that derived from dental pulp possess alkaline phosphatase activities. There were some lipid droplets in medium containing ascorbic acid 2-phosphate, dexametazon and Indometacin, that observed them by Oil-red-O staining. Here, we demonstrate the presence of a clonogenic cell population in dental pulp tissue. The cells within each colony were characterized by a typical fibroblast-like morphology. The frequency of colonyforming cells derived from dental pulp tissue was significantly higher in comparison to the incidence of bone marrow. In addition, the number of proliferating cells in DPSC (dental pulp stem cells) cultures was also significantly higher when compared with BMSC (bone marrow stem cells) cultures. In enzymatic method almost all of the cells are probably isolated but the damages are noticeable too. However, it is not surprising to observe different single colonies with different morphologies. There are some types of adherent cells in pulp tissue such as mesenchymal cells, fibroblasts and endothelial cells; which are able to proliferate. In order to investigate the effects of enzymatic digestion on cell isolation yield, in some samples, no enzyme digestion was performed. The results have shown that after culturing the enzyme digested pulp slices for 2 or 3 days, the first spindle-shape explanted cells were observed, but when the pulp slices from the same tooth are not treated by enzyme, the cells are observed after about 12 to 16 days.

\section{Discussion}

To determine the existence of such a cell in dental pulp, we applied methodology that had been previously developed for the isolation and characterization of BMSCs. Interestingly, DPSCs exhibited a higher proliferation rate compared with BMSCs in vitro. Our data also demonstrates the potential of DPSCs to form calcified deposits in vitro, as do BMSCs. However, DPSCs formed sparse and dense calcified nodules, and failed to develop lipidladen adipocytes, whereas BMSCs developed deposits and abundant lipid-laden adipocytic clusters extensive sheets of calcified. The data presented here demonstrate that postnatal dental pulp contains cells that are clonogenic, highly proliferative, and capable of regenerating a tissue, properties that effectively define them as stem cells Consequently, there is a great potential for the isolation of a large number of DPSCs from a single tooth that could be used for dentinal repair of a number of teeth.

Dental pulp contains a population of stem cells that called adontoblast. It seems that these cells synthesize and secrete the dentin matrix similar to adontoblasty cells that have been replaced. In the older pulps the numbers of undifferentiated cells were less and this reduces the ability of the pulp. The cells that isolated from other sources such as umbilical cord blood or bone marrow cells in comparison to pulp tissue showed less persistence. Pulp cells capable of survival in serum-free medium showed. As a result pulp cells differentiation rate is much more rapidly than the other two sources and gave acceptable results in treatments.

\section{Conclusion}

Despite the rapid findings and wealth of data provided by in vitro and in vivo approaches in the field of stem cells, further research studies are required. It is obvious that our knowledge in dental tissue engineering expands rapidly. In this study it has been demonstrated that Present dental pulp stem/progenitor cells have the ability to differentiate in vitro as well as in vivo into all kind of cells. There is still much to learn of the nature, potentiality and behavior of dental stem cells. DPSC (dental pulp stem cells) exhibited a spindle-like shape. The rate of cell division and cell morphology remained stable for 25 passages.

\section{Acknowledgments}

The authors acknowledge Hadi Mohammadi for technical support. This study was supported by Biotechnology lab, Nuclear Science and Technology Research institute, Tehran, Iran (NSTRI).

\section{References}

[1]. Gronthos S, Brahim J, Li W, Fisher LW, Cherman N, Boyde A, et al Stem cell properties of human dental pulp stem cells. J Dent Res, Aug 2002; 81(8): 531-535.

[2]. Sloan AJ, Smith AJ. Stem cells and the dental pulp: potential roles in dentine regeneration and repair. Oral Dis 2007; 13: 151-7.

[3]. Sveen OB, Hawes RR. Differentiation new odantoblasts and dentine bridge formation in rat molar teeth after tooth grinding. Arch Oral Biol, 1968; 13: 1399-1409.

[4]. Lainv G, GraZiano A, d'Aquino R, Pirozzi G, Lanza V, Valiantes S, et al. An approachable human adult stem cell source for hard tissue engineering, J cell physical, 2006; 206(3): 693-701.

[5]. Perets A, Baruch Y, Weisbuch F, Shoshany G, Neufeld G, Cohen S. Enhancing the vascularization of three-dimensional porous alginate scaffolds by incorporating controlled release basic fibroblast growth factor microspheres. J Biomed Mater Res A 2003; 65:489-97. 
The isolated stem cells after 2 months of culture

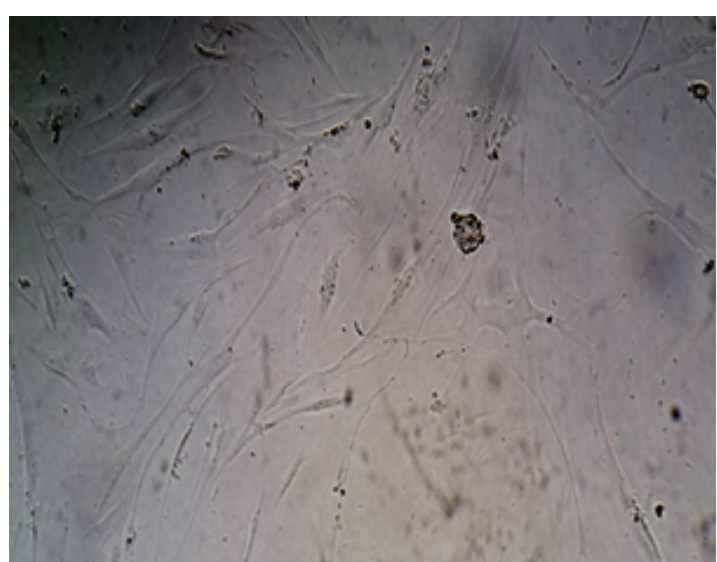

The human DPSCs after 14 day

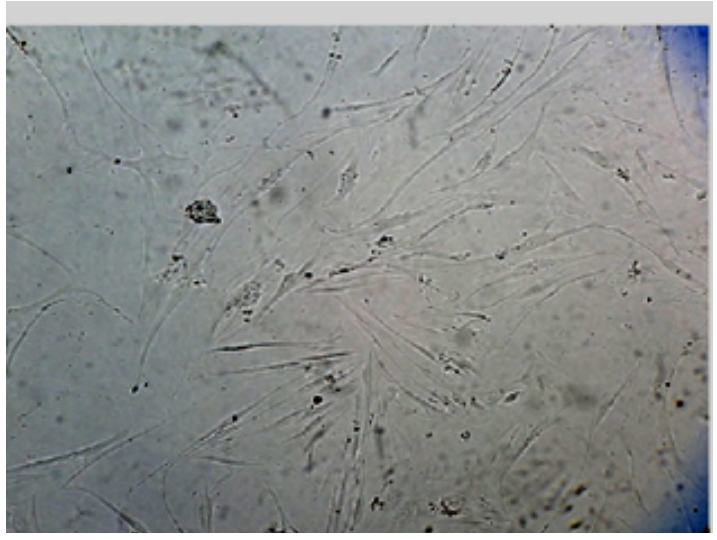

The human DPSCs after 30 day

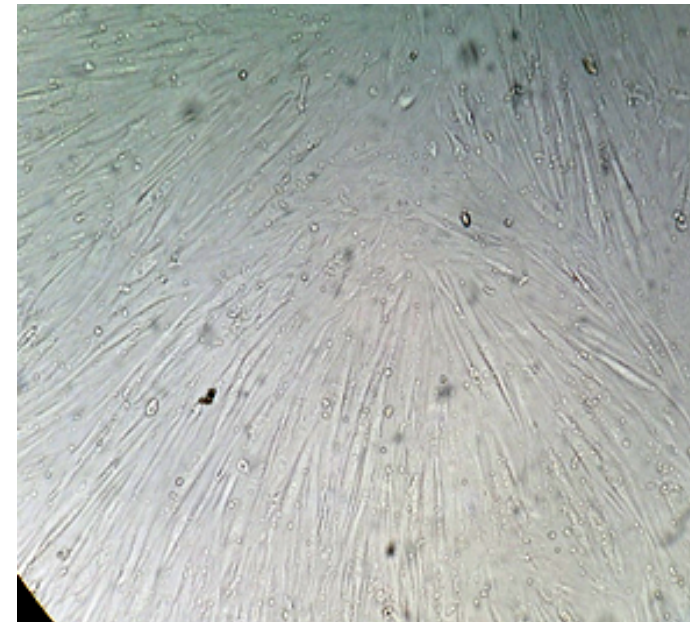

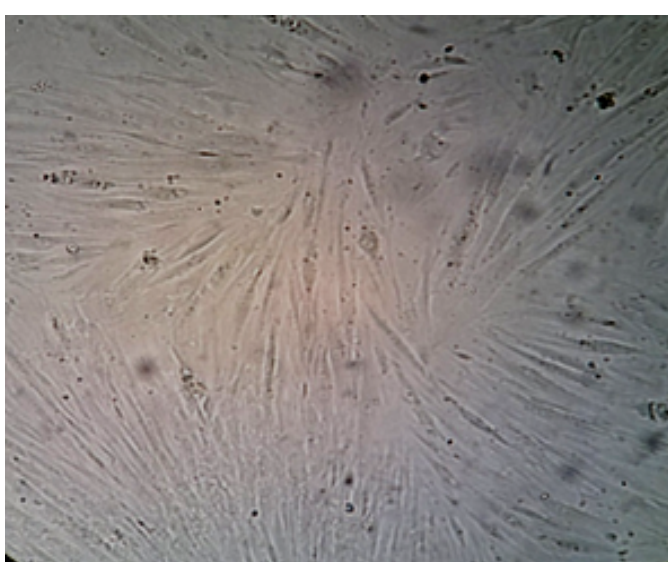

The human DPSCs after 21 day

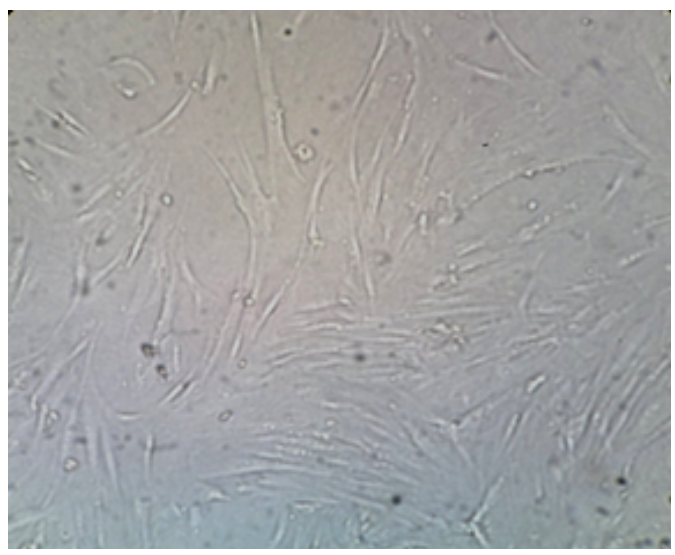

The human DPSCs after 50 day

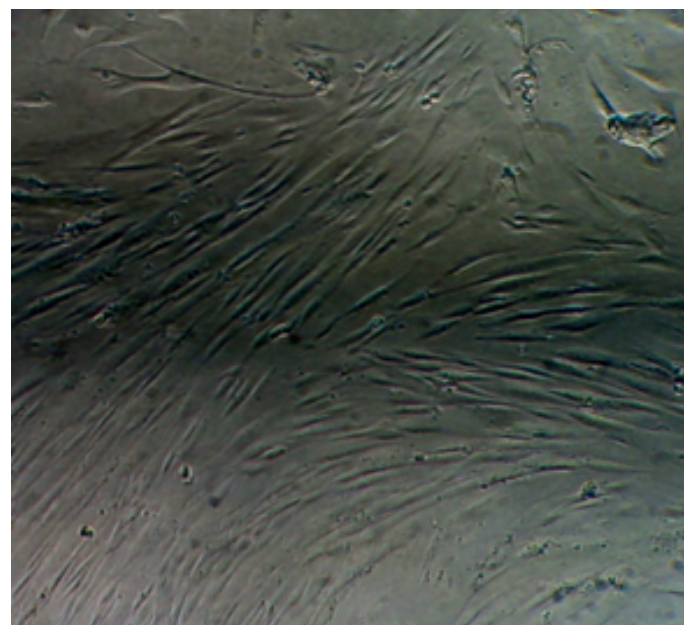


Bone marrows stem cells after 2 month of culture Bone marrows stem cells after 14 day

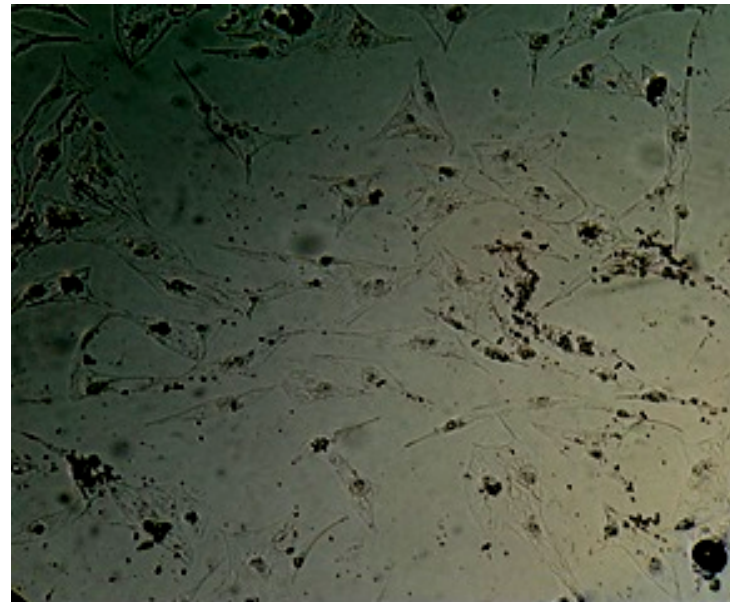

Bone marrows stem cells after 21 day
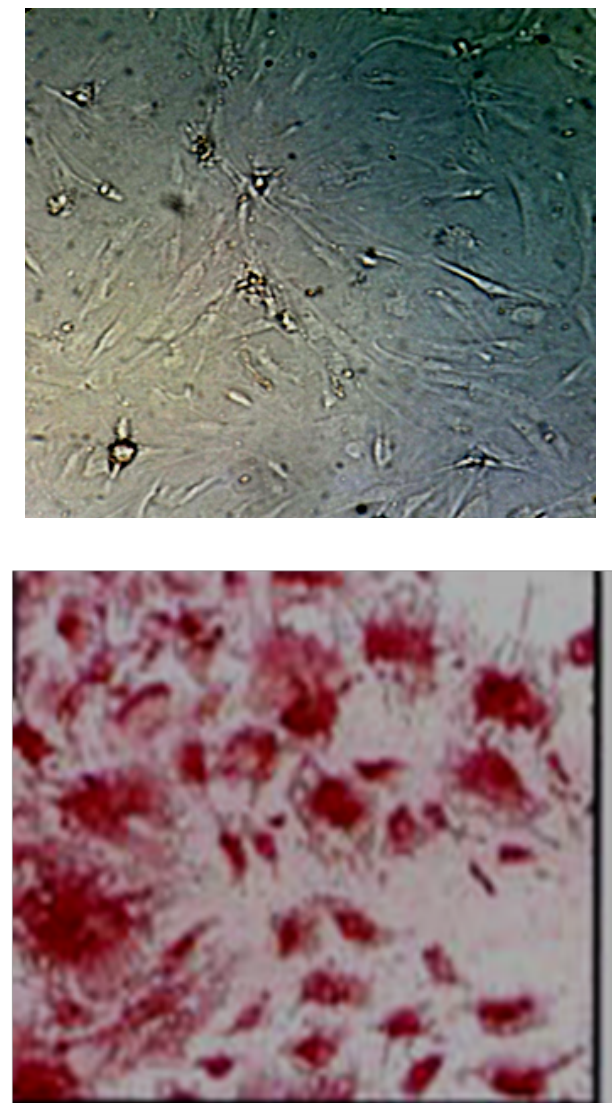

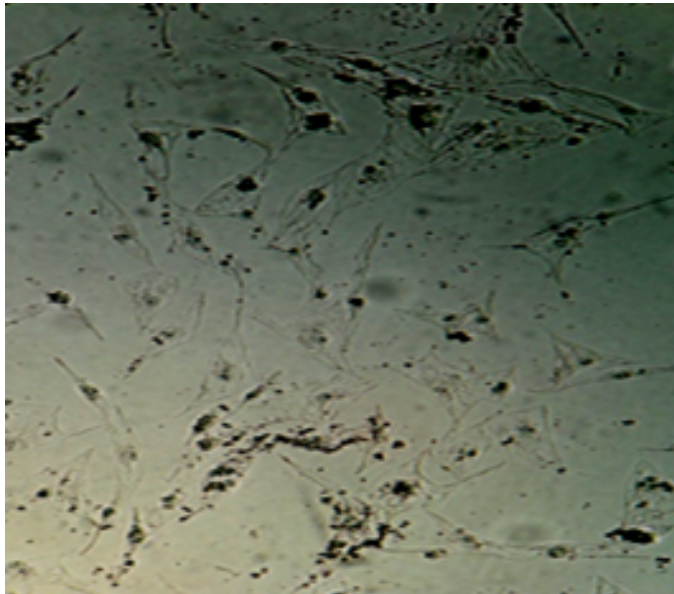

Bone marrows stem cells after 30 day
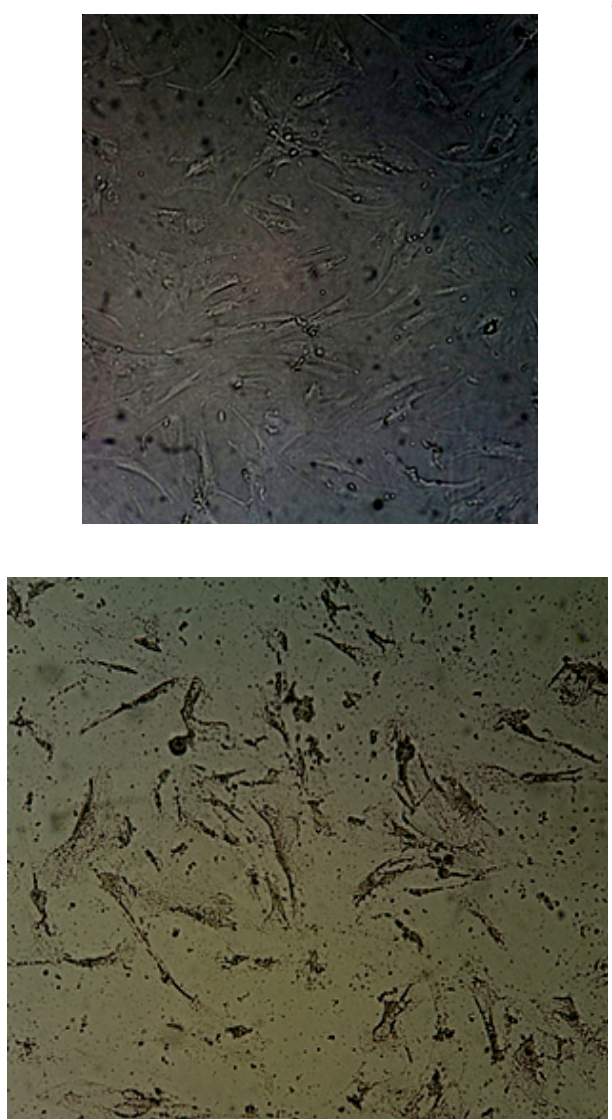

The human DPSCs after differentiation to osteosite
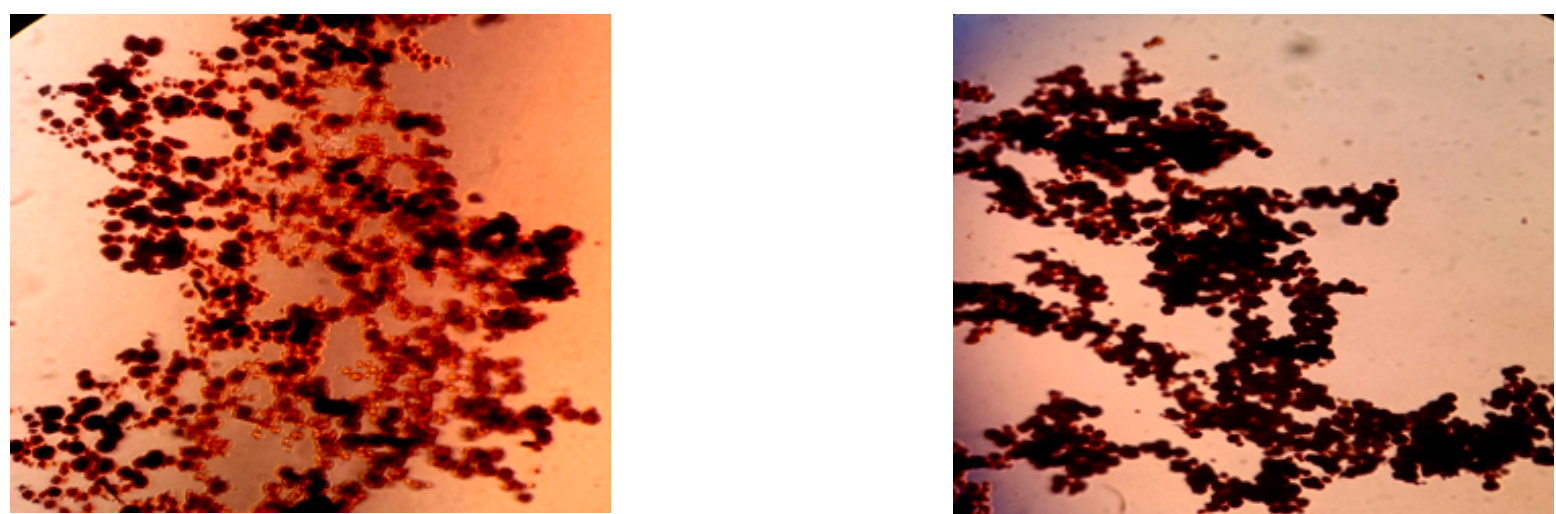
[6]. Ruch JV. Odontoblanst commitment and differentiation Biochem cell Bial. 1998; 76: 923-938.

[7]. Pandit A, Ashar R, Feldman D. The effect of TGF-beta delivered through a collagen scaffold on wound healing. 1999; 2: 89-100.

[8]. Taylor SJ, McDonald J. Controlled release ofneurotrophin-3 from fibrin gels for spinal cord injury. J Control Release 2004; 98: 281-94.

[9]. Utley D, Lewin S, Cheng E, Verity A, Sierra D, Terris D. Brain-derived neurotrophic factor and collagen tubulization enhance functional recovery after peripheral nerve transection and repair. Arch Otolaryn gol Head and Neck Surg 1996;122 - 407.

[10]. Novakovic G, Freed LE. Culture of organized cell communities. Adv Drug Delivery. 1998; 33: 15-30.

[11]. Feng Q, Chai C, Jiang XS, Leong KW, Mao HQ. Expansion of engrafting human hematopoietic stem/progenitor cells in three dimensional scaffolds with surface immobilized fibronectin. J Biomed Mater Res . 2006; 4: 781-91.

[12]. Tecles O, Laurent P, Zygovritsas S, Burger AS, Camps J, Dejou J, et al. Activation of human dental pulp progenitor stem cells in response to odontoblast injury. Arch Oral Biol, 2005; 50: 103-108.

[13]. Cordeiro MM, Dong Z, Kaneko T, et al. Dental pulp tissue engineering with stem cells from exfoliated deciduous teeth. J Endod. 2008;34:962-969.
[14]. About I, Bottero MJ, de Denato P, Camps J, Franquin JC, Mitsiadis JA. Human dentin production in vitro. Exp Cell Res. 2000; 258:3341.

[15]. Baghban Eslaminejad MR. Mesenchymal stem cells: history, isolation and biology. J Iran Anatomic sci. 2007;5(18):49-59.

[16]. Takeda T, Tezuka Y, Horiuchi M, Hosono K, Lida K, Hatakeyama $\mathrm{D}$, et al. Characterization of dental pulp stem cells, of human tooth germs. J Dent Res. 2008;87(7):676-81.

[17]. Nagatomo K, Komaki M, Sekiya I, Sakaguchi Y, Noguchi K, Oda $\mathrm{S}$, et al. Stem cell properties in human periodontal ligament cells. J Periodontal Res. 2006;41(4):303-10.

[18]. Coppe C, Zhang Y, Den Besten PK. Characterization of primary dental pulp cells in vitro. Pediatr Dent. 2009;319: 467-71.

[19]. Maria OM, Khosravi R, Mezey E, Tran SD. Cells from bone marrow that evolve into oral tissues and their clinical applications. Oral Dis. 2006;13:11-6.

[20]. Lindroos B, Maenpaa K, Ylikomi T, Oja H, Suuronen R. Characterisation of human dental stem cells and buccal mucosa fibroblasts. Biochem and Biophys Res Commun. 2008;368(2):329-35. 